\title{
Computer Simulation Principles of Combined-cycle Power Plants Start-ups Assignment Schedules
}

\author{
Yury A. Radin \\ All-Russian Thermal Engineering Institute \\ Moscow, Russian Federation \\ vti-unit@yandex.ru
}

\author{
Tatiana S. Kontorovich \\ All-Russian Thermal Engineering Institute \\ Moscow, Russian Federation \\ kontorovich_ts@mail.rud
}

\begin{abstract}
Combined Cycle Power Plant (CCPP) operation in power systems is characterized by the necessity of having a lot of shutdowns with subsequent start-ups from various thermal states.

CCPP start-up assignment schedules from various thermal states are developed on the base of the start-ups modes cycling analysis. At the same time the compliance with technology requirements is ensured. This also ensures maintaining the values of start-ups rate key indicators at a level close to the maximum allowable. Thus the maximum reduction of start-up duration is achieved.
\end{abstract}

The principal criterion of CCPP start-ups optimization is their duration based on any constraints that ensure the equipment reliability. Experimental testing of start-ups modes gives the possibility to identify the technology of their implementation.

Further improvement of start-ups process and start-up assignment schedules optimization are performed by calculation method. This paper describes the basic principles which can determine the automatic construction of CCPP start-up assignment schedules from various thermal states, which are able to change during start-up operations.

Keywords- combined-cycle power plant start-up assignment schedule; gas turbine unit; steam turbine; computer simulation

\section{INTRODUCTION}

The permissible number of cycles to failure, based on the equipment fatigue strength analysis is the modern approach to the combined cycle power plants (CCPP) start-ups optimization. The number of these modes, defining the CCPP life cycle, is the major characteristic of their flexibility giving an opportunity to prove a choice of a particular maintenance program and to use a particular start-up assignment schedule.

Development of the optimal start-up assignment schedule is reduced to the task of the start-up minimum duration while ensuring the required equipment life based on its fatigue strength conditions.

\section{The APPliCATION OF High LOAD PARTS OF EQUIPMENT FATIGUE STRENGTH ANALYSIS TO DESIGNING OF COMBINED CyCle POWER Plants START-UPS ASSIGNMENT SCHEDUles}

Equipment fatigue strength calculation is based on the hypothesis of linear damage summation according to which each type of fatigue cycles makes its contribution to metal wear.

The parameter, characterizing the permissible fatigue damage is evaluated in accordance with the relationship (1) [1]:

$$
\sum \mathrm{n}_{1} /\left[\mathrm{N}_{\mathrm{l}}\right]=\mathrm{n}_{1} /\left[\mathrm{N}_{1}\right]+\mathrm{n}_{2} /\left[\mathrm{N}_{2}\right]+\ldots+\mathrm{n}_{\mathrm{n}} /\left[\mathrm{N}_{\mathrm{n}}\right] \leq 1,
$$

where $n_{1}, n_{2} \ldots n_{n}$-the expected number of load cycles different types;

$\left[\mathrm{N}_{1}\right],\left[\mathrm{N}_{2}\right] \ldots\left[\mathrm{N}_{\mathrm{n}}\right]$ - the permissible number of load cycles different types.

The required number of load cycles and initial metal temperature are used to make a choice of initial steam temperature and the speed of its increasing. Special attention is paid to the steam flow as the greatest stresses may appear at the start-up initial stage.

The film coefficient value of the high pressure (HP) outlet superheater header is determined by the initial steam flow. The matter is that its thermal stress-strain state extremely affects the start-up operations duration especially at the initial start-up stage. Usually in this case the film coefficient value is not more $500 \mathrm{~W} /\left(\mathrm{m}^{2 \cdot} \mathrm{K}\right)$ and is appreciated as the steam flow through the open drains and blow down lines.

The initial steam temperature, providing the required number of load cycles "start-up - stationary operation - shutdown” is selected according to the known header metal initial temperature. Nomogram is presented in Fig. 1 to determine the header warming-up rate at the initial start-up stage corresponding to the selected difference between steam and metal temperatures.

The stresses, caused by the initial difference between the steam and the header metal temperatures, associated with high warming-up rate of the header's outer surface substantially higher than the quasi-stationary mode rate. 


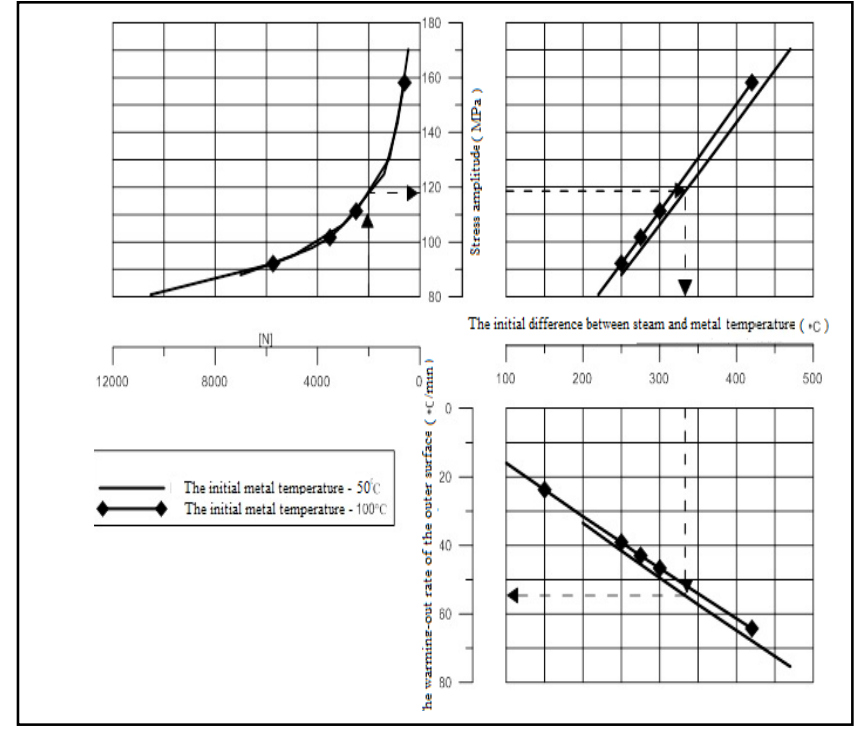

Fig. 1. Nomogram for determining the header 426x34 outer surface warming-up rate and the difference between steam and metal initial temperatures according to the number of "start-up - stationary operation shut-down” cycles

When the header metal temperature is equal to $50^{\circ} \mathrm{C}$, the film coefficient $\alpha=500 \mathrm{~W} /\left(\mathrm{m}^{2} \cdot \mathrm{K}\right)$ and the admissible number of load cycles $[\mathrm{N}]=2000$ the permissible initial steam temperature should not exceed $343^{\circ} \mathrm{C}$. It corresponds to the warming-up rate of the header outer surface $50 \div 55^{\circ} \mathrm{C} / \mathrm{min}$.

At the initial CCPP start-up stage steam temperature corresponds to the gas turbine unit (GTU) exhaust gases temperature and therefore to the initial gas turbine output.

\section{START-UP OUTPUT OF GAS TURBINE UNIT}

If there is no desuperheater in CCPP scheme the initial gas turbine load determines the heat recovery steam generators (HRSG) inlet gases temperature and the duration of maintaining this temperature at a predetermined level. That ensures warming-up of HRSG and steam turbine thick-walled elements. The GTU start-up output is determined by the dependence of its exhaust gas temperature from output and from this point of view is an analogue of power plant initial fuel flow concept. Under the power plant initial fuel flow consumption the amount of heat introduced with fuel is implied. This amount of fuel allows one to carry out the startup process from the fuel admission to a cold boiler and to steam turbine generator output increasing to its initial value.

For combined-cycle power plants with heat recovery steam generators the initial fuel flow value is determined by the GTU exhaust gases temperature dependence on its output. The HP superheater outlet header temperature is accepted as criteria when it is necessary to use the nomogram of GTU exhaust gases temperature and gas turbine start-up output selection (Fig.2). The fact is that the steam temperature should exceed the steam pipe metal temperature in HRSG outlet control section to avoid cooling of CCPP steam part.

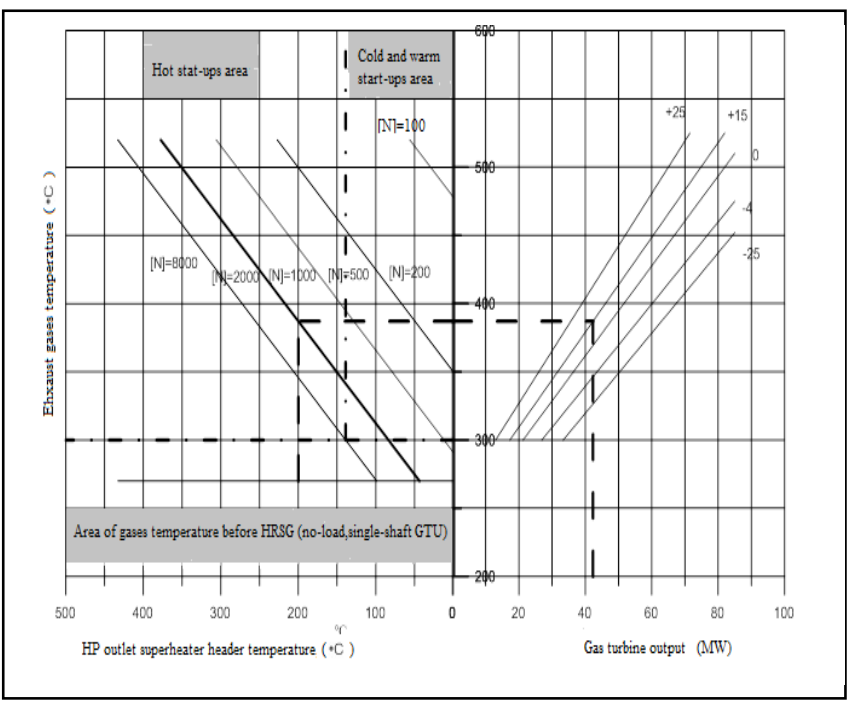

Fig. 2. Nomogram for determining the gas turbine start-up output depending on the high pressure superheater header $(426 \times 34 \mathrm{~mm})$ temperature

Nomogram (Fig.2) shows the example of CCPP-450 initial (start-up) load selection, which is depended on the initial temperature of the HP outlet superheater header 426x34 mm. In the first quadrant the permissible number of cycles is given, that is depended on the predetermined difference between the steam and the metal of the HP otlet superheater header (426x34mm) initial temperature. Hot and cold - warm start-ups areas are marked, depending on the initial metal temperature of the HP outlet superheater header. The correspondence between the exhaust gases temperature and the gas turbine output is shown in the second quadrant.

Temperature of the high pressure steam before its supplying to the steam turbine is another parameter necessary for the initial gas turbine load selection. According to the thermal stress-state calculations of the high pressure steam turbine T-150-7.7 rotor and high pressure rotors of steam turbine units the difference between the main steam and high pressure turbine cylinder temperatures before steam supplying to the turbine should be at $130 \div 150^{\circ} \mathrm{C}$ at warm and hot start-ups and at $350^{\circ} \mathrm{C}$ at cold ones.

\section{SUMMARY}

According to the cyclic strength calculations using a nomogram for GTU initial load selection gives the opportunity to automatically carry out CCPP start-up assignment schedules, with the required number of given type of cycles.

\section{REFERENCES}

[1] DIN EN 12952-3:2012-03

[2] Y. A. Radin, "Research and improvement of combined cycle power plants cycling,” doctoral thesis in Engineering Science, Moscow, 2013.

[3] A. F. Bogachev, Y. A. Radin, O. B. Gerasimenko, "Special aspects of operation and damaging of binary combined cycle power plants heat recovery steam generators,” Moscow: Energoatomizdat, 2008. 